\title{
What Teachers Say About Student Difficulties Solving Mathematical Word Problems in Grades 2-5
}

Daniel L. Pearce

Texas A\&M University - Corpus Christi

Faye Bruun

Texas A\&M University - Corpus Christi

Kimberly Skinner

Louisiana State University

Claricia Lopez-Mohler

Texas A\&M University - Corpus Christi

\begin{abstract}
This study investigated teachers' perspectives of difficulties students have solving mathematical word problems and causes of those difficulties. Classroom practices and strategies teachers used in their attempts to foster student problem solving success were also studied. Participants were 70 second-fifth grade teachers from 42 different schools in a south central region of the United States. Data included analyses of interview transcriptions of teachers' responses. Findings from teachers' responses showed students' abilities to read and understand the problem was the most frequently cited difficulty; standardized testing and text difficulties were the most cited causes of those difficulties. Examination of teachers' responses to practices and strategies used in the classroom revealed the most cited practice was working the problem independently and the most cited strategy taught to students was to identify key words. This study revealed the significant role reading plays in teachers' perspectives of students' difficulties solving mathematical word problems and provided insight into practices and strategies teachers reported using to teach word problems. With attention to teacher-reported causes of difficulties and importance of this ability for students, this study also showed the impact state mandated testing has on instruction of mathematical word problems.
\end{abstract}

Keywords: word problems, sources of students' mathematical difficulties, teacher views

In the last 20 years there has been an increase in the United States of the use of standardsbased education and the use of standardized testing as a means of student assessment. The No Child Left Behind (NCLB) Act of 2001 requires that all students be assessed in reading and mathematics in Grades 3 through 8. With this emphasis on mandatory testing as a means of determining student achievement, teachers are seeking ways to improve their students' performance on required tests. Student performance on mathematics assessments in the United States is an area of particular concern for educators as results of state-wide assessments reveal overall lower student scores in mathematics than other content areas. (TEA, 2011).

One such educator was a third-grade mathematics teacher who came and talked to the authors about the current state mandated mathematics test. During this conversation, she noted that the state's third-grade mathematics assessment was becoming increasingly a test of a student's ability to read and understand the problems instead of a test of computation skills. Intrigued, the authors examined the 2009 state released test since this was the most recent test available for public examination. We found that $28 / 40$ questions, or 70 percent of the test, 
were either word problems or contextualized problems which required reading (Texas Education Agency, 2009).

A search of the literature revealed that other regions in the United States included numerous word problems in their mathematics assessment. Edwards, Maloy, and Anderson (2009) examined word problems on the Massachusetts Comprehensive Assessment System (MCAS) fourth-grade mathematics test. They identified seven specific word- and comprehension-related challenges students faced when taking the test. Edwards and colleagues made suggestions for each of the seven areas and issued a call for others to examine state tests and identify word and comprehension challenges. Additionally, Jitendra, Sczesniak, and Deatline-Buchman (2005) stated that "both textbooks and state assessments require students to solve word problems" (p. 360).

Current interest in children's mathematics skills has led to research into the association between mathematical performance and reading skill. Many studies have focused on children with learning disabilities, such as Jordan, Kaplan, and Hanich (2002), which found in a twoyear longitudinal study that reading disabilities predicted children's progress in mathematics; however mathematics disabilities did not affect children's progress in reading.

Also of international concern, a study was conducted by Vilenius-Tuohimaa, Aunola, and Nurmi (2008) to investigate the association between mathematical performance and reading skill. Participants, children aged 9-10, were categorized as good or poor readers based on a norm-referenced, group-administered device for diagnosing reading difficulties. The results showed that performance on mathematical word problems was strongly related to performance in reading comprehension. The research suggested that both reading and mathematics skills required overall reasoning abilities. The reasoning strategies behind reading word problems have been related to the way in which the word problems are structured (Fuchs, Fuchs, \& Prentice, 2004).

The association between reading and mathematics ability has also been researched internationally for early childhood. Lerkkanen, Rasku-Puttonen, Aunola, and Nurmi's (2005) conducted a longitudinal study of children examined six times on mathematics and reading comprehension during the first and second years of primary school. The results showed that mathematics and reading comprehension were highly associated with each other across both years. Leppanen, Niemi, Aunola, and Nurmi (2006) found that kindergarten-aged children's counting ability predicted their text reading skills, word chain reading skills, and reading comprehension as fourth graders.

The presence of a high percentage of word problems on mathematics assessments led the authors to conduct a search of the literature on word problems and problem solving. We found that these problems have been alternately referred to in the literature as verbal arithmetic problems, story problems, word problems, and problem solving situations and that helping students read and understand these word problems has been a reoccurring topic in the professional literature for the last century.

Over eighty years ago, Buckingham (1925) wrote about the difficulty teachers had when teaching students to solve verbal problems in arithmetic. Weber (1966), likewise, wrote about the difficulty students and teachers had with arithmetic word problems, labelling them "demon problems" (p. 314). In a chapter included in Problem Solving in School Mathematics: 1980 National Council of Teachers of Mathematics Yearbook, Davis and 
McKillip (1980) described ways to improve the solving of story problems in elementary schools. The yearbook also included a multi-page bibliography on problem solving in school mathematics (Mason, 1980). More recently, Pearce and Reynolds (2004) compared the word problem recommendations contained in 1970s content area reading textbooks with those of textbooks from the 2000s. They found that the textbooks contained numerous specific recommendations for helping students read and solve mathematical word problems. Interestingly, it appears that the mathematics community has addressed the topic of word problems under the larger concept of problem solving since the 1980s. In an examination of mathematics education textbooks, Pearce and Bader (2001) found that suggestions for teachers and students were labelled as problem solving instead of word problems.

One call for classroom attention to problem solving strategies came from the National Council of Teachers of Mathematics (2000), which contended in its widely-read and cited Principles and Standards of School Mathematics, "Students need to develop a range of strategies for solving problems, such as using diagrams, looking for patterns, or trying special values or cases. These strategies need instructional attention if students are to learn them" (p. 2). The Standards also suggested that teachers give students opportunities for the application of problem solving strategies across all mathematics content areas.

In NCTM's Curriculum Focal Points for Prekindergarten through Grade 8 Mathematics (2006), problem solving continues to be a key theme. While recent literature on best practices for problem solving in mathematics is prolific (Cifarelli \& Sheets, 2009; Edens \& Potter, 2008; Immergut, 2003; Sanchez, Encinas, Fernandez, \& Sanchez, 2002), no current information was found on how elementary teachers are addressing mathematical word problem instruction for their students.

Available information confirmed the notion that United States' elementary mathematics state mandated assessments incorporated word problems which required increased reading ability rather than computation skills. In addition, current information on teachers' perspectives of student difficulties with word problem solving is scarce. The purpose of this study was to identify what elementary teachers reported as difficulties their students have when solving mathematical word problems and the causes of those difficulties. This study also investigated what classroom practices and specific strategies teachers use in their attempts to foster student problem-solving success. The implication for teacher education is that teachers will be provided with instructional attention to the association of mathematics and reading word problems.

\section{Methods}

This research was conducted at a 4-year university in the south central region of the United States where hundreds of teachers attend classes, workshops, and meetings. The following research questions guided this investigation of elementary teachers' perspectives and reported practices concerning their students' abilities to solve word problems:

(1) What are teachers' perspectives on the difficulties their students have when solving mathematical word problems?

(2) What are teachers' perspectives on the causes of students' difficulties their students have when solving mathematical word problems? 
(3) What do teachers report as the classroom practices they use for teaching students to solve mathematical word problems?

(4) What specific problem solving strategies do teachers report teaching to their students for solving mathematical word problems?

\section{Participants}

The participants in this study were 70 elementary teachers who taught mathematics in Grades 2-5. The authors chose to limit the study to the second- through fifth-grade levels because students in kindergarten and first-grade were not as likely to be given written word problems to solve and students above the fifth-grade were more likely to be in middle schools with departmentalized mathematics classes. The education levels of the teachers who participated in this study consisted of 43 teachers with a bachelor's degree and 37 teachers who had taken graduate courses or had earned a master's degree. Thirty-nine teachers had less than 10 years of teaching experience and 31 teachers had 10 years or more of experience. The sample included 13 second-grade teachers, 21 third-grade teachers, 19 fourth-grade teachers, 15 fifth-grade teachers, and 2 teachers who taught more than one grade level. The teachers represented 42 campuses from 16 different public school districts, 2 charter schools, and 1 private school.

Participants were recruited through two procedures: (1) teachers taking graduate course work at the university who taught Grades 2-5 were asked to participate in interviews on mathematics word problems, and (2) a general call went out to former graduate students and public school contacts asking for help in soliciting Grade 2-5 teachers willing to participate in the study. The participants who taught mathematics were individually interviewed.

\section{Procedure}

Data was gathered through the use of an interview guide. Johnson and Christensen (2012) described an interview guide as a common protocol that an interviewer follows while interviewing subjects. The inclusion of an interview protocol and a series of open-ended questions allow the interviewer to obtain both quantitative and qualitative data. The authors constructed an interview guide for use in teacher interviews that consisted of an interview protocol and open-ended questions which addressed the purpose of the study.

The completed interview guide was examined by two professors of education and two elementary teachers not involved in the study, who checked the guide and questions for clarity and completeness. Based upon their feedback, all dichotomous or unclear questions were eliminated or rewritten. The final interview guide contained the protocol and 12 openended questions, which were then field-tested on two graduate students. The interview guide is included in the Appendix and the interview questions are presented in Table 1.

The authors adhered to the guide for asking questions while interviewing participants. In total, 70 elementary teachers were individually interviewed by the authors. Each teacher signed a consent form, each interview was audio-recorded, and interviews were transcribed. Researcher kept notes for all interviews and participants.

The authors independently conducted a content analysis of the transcriptions of the teacher interviews to determine the commonalities and trends. For this study, we began with 
an a priori approach to content analysis. The first step in the content analysis was the creation of an a priori checklist that contained 12 categories based on the open-ended questions and the purpose of the study. One category existed for each of the 12 questions in the interview guide. This is consistent with Stemler's (2001) recommendations for conducting a content analysis. The authors then did an initial content analysis using the a priori categories on seven of the transcripts. This was done to determine whether the a priori categories were appropriate. The coding process consisted of the authors independently reading the seven transcripts and identifying units of meaning and designating them into appropriate categories. The authors met and compared coded information on the seven transcripts analyzed. Lincoln and Guba (1985) suggested the checks and balances inherent in team-based data analysis increase the trustworthiness of the analysis. The authors found $83 \%$ degree of agreement on the designated information from the transcripts and some disagreement on placement in categories. The authors examined the coded information and arrived at an amended set of categories. The content checklist was modified from the original 12 categories into seven categorical areas concerning mathematics word problems that related back to the research questions posed: 1) teachers' perspectives of student difficulties and 2) teachers' perspectives of the causes of student difficulties which related to the first two research questions; 3 ) teacher reported classroom practices, which answered the third research question; 4) teacher reported specific instructional strategies which concerned the fourth research question.

Table 1

Teacher Interview Questions

Interview Questions

1. Describe any difficulties that your students have when working mathematical word problems.

2. How important is the ability to solve word problems for your students?

3. What do you think the cause of their difficulty to solve word problems is?

4. How do you feel about teaching word problems?

5. How would you rate your success in teaching students to solve word problems?

6. What specific strategies do you use when teaching word problems?

7. Where did you learn them?

8. What specific strategies do you teach the students to use to solve word problems?

9. Where did you learn them?

10. What would you consider your best method for teaching word problems?

11. Has the emphasis on word problems changed in the past few years? Why or why not?

12. Approximately how many hours of in-service dealing specifically with working with word problems have you had in the past three years?

The authors then independently reread all 70 transcripts and placed the coded information into the appropriate revised categories. The authors found agreement on the categorization of coded information. In the instances when the authors disagreed on the categorization of content, the authors reexamined the transcripts and reached consensus.

\section{Results}

The findings from the interviews with Grade 2-5 teachers were tabulated and compared. Table 2 includes the findings from the analysis of teachers' responses when asked in 
Question 1 of the interview guide to describe any difficulties that their students have when working mathematical word problems. Most teachers reported more than one reason for their students' difficulties.

Almost half of teachers' responses (45\%) indicated that solving math word problems is difficult for students because students struggle with reading and understanding the problems. Two other difficulties cited in teachers' responses involved students' inability to make a plan to solve the problem (35\%) and a lack of vocabulary knowledge (13\%). In contrast, only one teacher indicated that computation was a problem.

Table 2

Teacher Reported Student Difficulties

\begin{tabular}{lccccccc}
\hline Difficulty & Grade 2 & Grade 3 & Grade 4 & Grade 5 & Multi Grades & Total & $\%$ \\
\hline $\begin{array}{l}\text { Reading and understanding } \\
\text { the problem }\end{array}$ & 7 & 15 & 11 & 10 & 0 & 43 & 45 \\
Making a plan & 7 & 9 & 10 & 5 & 2 & 33 & 35 \\
Vocabulary & 2 & 4 & 4 & 2 & 0 & 12 & 13 \\
Background knowledge & 0 & 0 & 1 & 2 & 0 & 3 & 3 \\
Determining reasonableness & 0 & 1 & 0 & 1 & 0 & 2 & 2 \\
Computation & 0 & 1 & 0 & 0 & 0 & 1 & 1 \\
Higher level thinking & 0 & 1 & 0 & 0 & 0 & 1 & 1 \\
\hline
\end{tabular}

Presented in Table 3 are the findings from the analysis of teachers' responses when they were asked in Question 3 of the interview guide about their perspectives of the causes of student difficulties when solving word problems. As in Table 2, most teachers provided more than one reason for the cause for their students' difficulties.

Table 3

Teacher Reported Causes of Student Difficulties

\begin{tabular}{lccccccc}
\hline Cause of Difficulty & Grade 2 & Grade 3 & Grade 4 & Grade 5 & Multi Grades & Total & $\%$ \\
\hline Standardized testing & 4 & 11 & 9 & 12 & 1 & 35 & 29 \\
Text difficulty & 3 & 5 & 8 & 9 & 2 & 28 & 24 \\
Previous teachers & 2 & 5 & 5 & 8 & 0 & 20 & 17 \\
Student factors & 3 & 5 & 6 & 3 & 1 & 18 & 15 \\
Family/language factors & 3 & 3 & 2 & 3 & 0 & 11 & 9 \\
School curriculum & 1 & 1 & 0 & 2 & 0 & 4 & 3 \\
Teacher training & 1 & 1 & 0 & 1 & 0 & 3 & 3 \\
\hline
\end{tabular}

As Table 3 shows, responses that addressed the causes of student difficulties fell into four primary areas: standardized testing (29\%), text difficulties (24\%), previous teachers $(17 \%)$, and student factors (15\%). Family/language factors (9\%), school curriculum (3\%), and teacher training (3\%) were the least teacher-reported causes of student difficulties.

Table 4 contains the findings from the analysis of teachers' responses about the classroom practices the teachers used for teaching word problems. The data analyzed came from interviewee responses to Questions 4, 5, 6, and 10 of the interview guide concerning what practices the teachers used when teaching word problems and which practice they would consider as their best method. Some teachers reported more than one classroom practice. 
The teachers identified nine different classroom practices they used for problem solving instruction, with the responses varying only slightly across grade levels. Having the students solve the word problems independently (37\%) was the most frequently cited practice; cooperative grouping (21\%) and manipulatives (19\%) were also reported as classroom practices for math word problem instruction.

Table 4

Classroom Practices for Math Word Problem Instruction

\begin{tabular}{lccccccc}
\hline Classroom Practice & Grade 2 & Grade 3 & Grade 4 & Grade 5 & Multi Grades & Total & $\%$ \\
\hline $\begin{array}{l}\text { Work problem } \\
\text { independently }\end{array}$ & 6 & 8 & 8 & 7 & 1 & 30 & 37 \\
Cooperative grouping & 3 & 4 & 5 & 5 & & 17 & 21 \\
Manipulatives & 3 & 5 & 4 & 3 & 1 & 16 & 19 \\
Modelling & 2 & 2 & 1 & 2 & & 7 & 9 \\
Writing own problems & & & 4 & 1 & & 5 & 6 \\
$\begin{array}{l}\text { Practice with real life } \\
\text { problems }\end{array}$ & 1 & & 1 & 1 & & 3 & 4 \\
Math journals & & 1 & 1 & & & 2 & 2 \\
Accessing prior & & & 1 & & & 1 & 1 \\
knowledge & & & & & & 1 & 1 \\
Chants & & 1 & & & & & \\
\hline
\end{tabular}

The findings from the analysis of teachers' responses when they were asked, in Question 8 of the interview guide, what strategies they taught their students to use when solving word problems are contained in Table 5. Many teachers reported teaching more than one strategy to their students.

Table 5

Specific Strategies Taught to Students for Solving Word Problems

\begin{tabular}{lccccccc}
\hline Strategy & Grade 2 & Grade 3 & Grade 4 & Grade 5 & Multi Grades & Total & $\%$ \\
\hline Identify key words & 5 & 11 & 8 & 13 & 2 & 39 & 21 \\
Draw a picture & 6 & 11 & 12 & 6 & 1 & 36 & 19 \\
Steps procedure & 10 & 10 & 11 & 3 & 1 & 35 & 19 \\
Reword/reread & 7 & 10 & 8 & 4 & 2 & 31 & 17 \\
Make table/list & 1 & 4 & 6 & 3 & 1 & 15 & 8 \\
Act it out & 1 & 6 & 1 & & & 8 & 4 \\
Visualize the problem & 1 & 4 & 2 & 1 & & 8 & 4 \\
Work backward & & 2 & 1 & 2 & & 5 & 3 \\
Choose operation & & 3 & 1 & & & 4 & 2 \\
Guess, test, revise & 1 & & 3 & & & 4 & 2 \\
Work a simpler problem & & & 2 & & & 2 & 1 \\
\hline
\end{tabular}

The most popular strategy reported by teachers was teaching the students to identify key words in the text, (21\%). Draw a picture (19\%), steps procedure (19\%), and reword/reread $(17 \%)$ were also three specific strategies taught to students for solving word problems. 


\section{Discussion}

The purpose of this study was to identify what elementary teachers reported as the difficulties their students have when solving mathematical word problems and the causes of those difficulties. This study also investigated what classroom practices and specific strategies teachers stated they used in their attempts to foster student problem solving success.

\section{Teacher Reported Student Difficulties}

The findings that addressed the first research question concerning teachers' perspectives on the difficulties their students have when solving mathematical word problems revealed that almost half of teachers indicated that their students struggled with reading and understanding the problems. A fourth year teacher offered this explanation for her students' difficulties, "It's the reading. Just being able to read and comprehend the words, the vocabulary, the terms of the math problems." In contrast, only one teacher responded that computation was a problem. This is consistent with Braselton and Decker's (1994) findings that students' ability to read and comprehend the mathematical text is necessary before they can apply mathematical skills. They concluded that reading in math class, "is a complex mixture of words, numbers, letters, symbols, and sometimes graphics" (p. 276). Hoff (2001) established that poor readers struggle in mathematics class because of learning disabilities, limited English proficiency, or lack of reading skills.

\section{Teacher Reported Causes of Student Difficulties}

Responses that addressed the causes of students' difficulties fell into four primary areas: standardized testing, text difficulties, previous teachers, and student factors. In this study, standardized testing is defined as the emphasis placed on the state mandated test which is given annually to students in Grade 3 through Grade 8. Many teachers stated the assessment has undergone substantial content changes in recent years; one third-grade teacher reported, "now all of the mathematics tests involve reading." A third-grade teacher commented, "in the past, perimeter would be on the test as a measurement problem around a square. Now it is a word problem on the test."

The second most-cited cause of the students' difficulties reported by teachers was the word problem texts. Text difficulties referred to the words and context used in problems from the textbook or other curricular materials that the students had to solve. Numerous teachers' responses noted that the problems were not "real world," and not relative to their students' experiences. A second aspect of text difficulty was that the problems the students needed to solve were complex and frequently involved more than one step. This made the problems harder for the students to read and solve. One fifth-grade teacher explained that, "sometimes the students do not read the problem carefully to realize it's a two step problem. They just do what they saw first and don't think about what the problem is really asking."

Another frequently reported cause of student difficulty was the teaching done by previous teachers. Teachers' responses indicated that the students had a weak foundation because the previous teachers did not teach the basics adequately. A veteran fourth-grade teacher explained, "In fourth-grade they are going to two-step problems and they just don't catch it. 
What's happening is your first and second-grade is taught key words and that is what they are hanging on to." Other upper grade teachers also felt that the students' previous teachers taught students to read for key words, which did not always transfer to success with more complex problems. This is consistent with the findings of Xin and Zhang (2009), who found that students often fail to transfer skills they learned in solving simple problems to more complex ones.

An unexpected finding that emerged from the teachers' responses on their students' difficulties and the causes of those difficulties was that many of the frustrations the teachers expressed were almost entirely concerned with factors outside of their control (e.g., state mandated tests, school curriculum/textbooks, teacher training, and previous teachers). In contrast, excluding reading ability, fewer comments related to student factors as causes (e.g., background knowledge, interest, vocabulary, and computation ability). This is in contrast to Bingolbali, Akkoç, Ozmantar, and Demir (2011) who in their study found that elementary teachers blamed mathematical difficulties on student related factors such as lack of economic situation, family interest, or friends.

\section{Classroom Practices for Math Word Problem Instruction}

Findings for the third research question, that considered what teachers reported as the classroom practices they used for teaching students to solve mathematical word problems, revealed the teachers identified nine different classroom practices they used for problem solving instruction, with the responses varying only slightly across grade levels. Having the students solve the word problems independently was the most frequently cited practice. This independent work was often mentioned as following teacher modelling of problem solving strategies, but teachers did not state the number of examples demonstrated or the regularity of prior modelling. A fourth-grade teacher who reported teaching at a low socioeconomic status school explained her instruction for teaching students to solve word problems as, "They identify the question. They identify the numbers and labels and I teach them to identify the key words and then to solve their problems and identify their answers." Other practices reported were cooperative grouping and use of manipulatives. While neither cooperative grouping nor using manipulatives can be thought of as new ideas, apparently the majority of teachers interviewed are not incorporating using them into teaching word problems. Additionally, a surprisingly small number of the teachers stated that they had the students write their own problems $(6 \%)$ or practice with real life problems $(4 \%)$. These findings suggest that the majority of elementary teachers are not utilizing practices that have been researched and found to have positive effects, such as those elucidated in professional literature on reading and writing with mathematics (Gutstein, 2006), using real life contexts (Bates \& Wiest, 2004), personalized story problems (Hart, 1996), and using manipulatives with writing and discussing mathematics (Kosko \& Wilkins, 2010). The lack of teacher use of writing when teaching word problems is also interesting because the data in this study agree with the findings from a previous study conducted on junior high mathematics teachers' use of writing in mathematics class (Pearce \& Davidson, 1988). While focusing on teachers in slightly different grade levels, both studies found the use of writing in mathematics 
instruction was not a frequently occurring instructional activity. Apparently, teacher use of writing in mathematics instruction has not significantly changed in more than two decades.

\section{Specific Strategies Taught to Students for Solving Word Problems}

The fourth research question focused on what specific problem solving strategies teachers reported teaching to their students to solve mathematical word problems. While no single strategy was taught to the students by a majority of the teachers, the most popular strategy reported by teachers was teaching the students to identify key words in the text, by circling, underlining, or highlighting this information. A third-grade teacher with five years of experience described the strategies she used, "I teach them to look for key words. I teach them to highlight the key words on their paper, to underline the key words, and try to cross out any information in the problem that they do not need to use. By circling the numbers and underlining the key words it kind of maps out their problem." This is especially troublesome in light of Jonassen's (2003) research on problem solving strategies. He found that the search for key words strategy was common in classrooms where students had little problem solving success, and that this strategy was taught and re-taught to struggling math students year after year in spite of their lack of success.

The authors were surprised by the data on problems solving strategies reported by the teachers. Though all of the teachers interviewed for this study teach in a state where the state's content standards are specified by grade level and discipline, not one of the 70 teachers interviewed reported teaching every problem solving strategy expected to be taught at their respective grade level. While the authors expected to find some individual variance in teacher problem solving strategy instruction reported by those interviewed, a wider range of application of strategies was anticipated, due to the NCTM's Principles and Standards of School Mathematics (NCTM, 2000) that stressed the need for students to practice a wide range of strategies. These findings on teachers' instruction of problem solving strategies are a concern, as numerous classroom-based studies have shown the explicit strategy instruction benefits student problem solving ability (Hembree, 1992; Higgins, 1997; Oladunni, 1998, Schoenfeld, 1979). In addition, there is a body of literature about the teaching of reading strategies in math class (Hyde, 2006), though the data acquired in this study found that teacher use of these strategies was scarce.

The teachers interviewed painted a picture of being largely left to develop and find their own practices and strategies. More than a third of the teachers' responses to where they had learned the strategies they used indicated that they learned strategies informally, from other teachers or as a result of personal experience (often termed "trial and error"), than from any other source. A third-grade teacher entering her second year of teaching responded that she learned the strategies of rereading, drawing a picture, and acting it out by trial and error. "Nobody told me what to do. Nobody helped. I just figured out that they didn't understand the basic reading of the problem and that I had to do something or I would be a gigantic failure. So, totally trial and error for my own survival and my students' survival." Other teachers relied on their fellow teachers to know what to do. A fourth-grade teacher with four years of experience at that grade level explained that she taught her students, "a system where we set up the problem" that focused on identifying the operation needed to solve the problem. When 
asked where she learned this strategy, she replied that she "learned this from other teachers. Basically, from my group that I work with, my colleagues that have been here longer than I have." This response is consistent with Rousseau's (2004) findings that collegial interactions and relationships within a school influence how mathematics is taught in the classroom and Superfine's (2009) study that showed teacher experience can directly affect curricular use. Other recent mathematics classroom research studies have examined the ways in which teacher beliefs about mathematics impact classroom practices (Rousseau, 2004) and the relationship between lesson study and mathematics teachers' self-efficacy (Sibbald, 2009).

One third of the teachers' responses revealed they had used strategies presented by someone at an in-service training or workshop and the majority of those responses referred to the use of step procedures developed by individuals and presented at in-service presentations to schools. While often renamed or including an additional step, all the step procedures identified in the study have similarities to Polya's (1945, 2009) four-step model: 1) understanding the problem, 2) devising a plan, 3) carrying out the plan, and 4) checking for reasonableness.

Additionally worth noting were the two teachers who reported they had learned the strategies they currently use to teach problem solving in the classroom from their own schooling. One fourth-grade teacher with one year of experience, who taught her students "when in doubt, draw it out," reported that she learned this strategy from "when I was in school. When I was in elementary and high school." This is consistent with the finding of Stuart and Thurlow's (2000) research on preservice teachers' classroom practices which found that many teachers teach the way they were taught as students.

What about the teacher guide for the district-adopted textbook? Only 10 teachers' responses reported that they had learned problem solving strategies from the teacher guide that accompanies the math textbook. Superfine's (2009) research on the role of teacher experience in the use of curriculum materials seems to apply here as well, as her study revealed that the teacher guide was not extensively used by the teachers for the planning or enactment of math lessons. She found that teachers, instead, relied on their previous experiences and their personal conceptions of math teaching and learning when making instructional decisions. A fourth-grade teacher interviewed for this study explained that her instructional strategies for teaching problem solving developed, "through my own difficulties, from what I knew worked best for me, my own personal experience."

Based upon this study's findings, the teachers interviewed are very aware of the presence of word problems on the state's mathematics tests. Interestingly, though numerous authors have investigated the relationship between solving word problems and student success in mathematics, including Jitendra, Sczesniak, and Deatline-Buchman (2005), mentioned earlier, only one out of ten responses alluded to that connection. Success on the current state mandated test was of the most importance to teachers.

This finding seems to confirm the argument that as the shift away from local control of schooling and curriculum continues; the state mandated test increasingly controls what is considered important and goes on in the classroom (Herman, 1998; Kohn, 2001). Within the sample of teachers we interviewed even some second-grade teachers, who did not give a mandated standardized test at their grade level, felt the pressure from the test" One secondgrade teacher responded that her students' ability to solve word problems was, "very 
important because many of their tests in the future will come with lots and lots of word problems." She later added, "We try not to teach the test, but it is so driven that they are able to do these things." When this response is combined with other responses, such as that of a third-grade teacher mentioned earlier who commented that, "now all of the mathematics test involves reading," it indicates the extent to which the teachers interviewed are aware of the presence of word problems.

\section{Limitations of the study}

This study's findings had two limitations. The first limitation involved data gathering, as the data were gathered through interviews and not direct observation. While interviews and self-reported data are not always an accurate reflection of classroom practices, the authors' experiences suggest that the data gathered were representative of classroom instructional practices. The second limitation was the fact that the teachers interviewed were volunteers, the majority of whom $(63 \%)$ had been recruited through graduate courses. However, because the 70 teachers interviewed came from 42 separate campuses and represented four different grade levels, the authors found the responses of the recruited teachers to not be noticeably different from those not in graduate classes.

\section{Implications for Further Research}

Findings revealed by this study show that there are some major implications for further research. First, were the teachers interviewed for this study representative of elementary teachers from a different region of the United States? Second, the findings of this study raise questions about actual teacher classroom practices and whether they are similar to what the teachers reported. Finally, if reading is an area of student difficulty, how is reading taught in math class? In addition to needing more information on teacher classroom practices, the entire area of word problem instruction appears to be a fertile ground for future investigation.

\section{Summary}

The increased presence of word problems on the state mandated mathematics test was the impetus for this study and thus this study investigated what elementary teachers reported as the difficulties their students have when solving mathematical word problems and the causes of those difficulties. This study also investigated teachers' perspectives on what classroom practices and specific strategies they use in their attempts to foster student problem solving success.

Findings from the teachers' responses showed that their students' ability to read and understand the problem was the most frequently cited student difficulty. Responses concerning the teachers' perspectives of the causes of those difficulties fell into four primary areas: standardized testing, text difficulties, previous teachers, and student factors. Examination of teachers' responses to the practices and strategies they used in the classroom to teach students to solve word problems revealed the most cited classroom practice was working the problem independently and the most cited strategy taught to students was to 
identify key words; however, none of the teachers interviewed reported teaching all the problem solving strategies required by the state standards to be taught at their grade levels. Based upon the results of this study, the teachers interviewed were aware of the increased emphasis on word problems on the state assessment.

When analyzing the transcripts of the interviews, one aspect became very clear. The teachers spent more time talking about problems and/or difficulties than they did about practices or strategies used in their classrooms. In one sense, it seems to confirm Weber's comments about "demon story problems" (1966). Griffin and Jitendra (2009) argued that the process of problem solving is much more complex than solving an equation with numbers pulled from a word problem, so problem solving instruction must be carefully designed. The overwhelming majority of teachers interviewed for this study expressed an interest in learning additional information on how to teach their students to solve word problems. This is also confirmed by the finding that five teachers reported they had turned to the internet and personal research to learn strategies to teach students to be successful problem solvers. One teacher summed this up by saying, "I would feel a lot better if I had a better method to teach them."

This study revealed the significant role reading plays in teachers' perspectives of students' difficulties solving mathematical word problems and it also provided insight into the practices and strategies teachers' reported using to teach word problems. With attention to the teacher-reported causes of the difficulties and the importance of this ability for students, this study also showed that standardized testing has greatly impacted classroom instruction of mathematical word problems.

\section{References}

Bates, E. T., \& Wiest, L. R. (2004). Impact of personalization of mathematical word problems on student performance. The Mathematics Educator, 14(2), 17-26.

Bingolbali, E., Akkoç, H., Ozmantar, M. F., Demir, S. (2011). Pre-service and in-service teachers' views of the sources of students' mathematical difficulties. International Electronic Journal of Mathematics Education, 6(1), 40-59.

Braselton, S., \& Decker, B. C. (1994). Using graphic organizers to improve the reading of mathematics. The Reading Teacher, 48, 276-281.

Buckingham, B. R. (1925). Selecting and evaluating arithmetic problems. Educational Research Bulletin, 4(2), 34-37.

Cifarelli, V., \& Sheets, C. (2009). Problem posing and problem solving: A dynamic connection. School Science and Mathematics, 109, 245-246.

Davis, E. J., \& McKillip, W. D. (1980). Improving story-problem solving in elementary school in mathematics. In S. Krulik \& R. E. Reys (Eds.), Problem solving in school mathematics: 1980 NCTM yearbook (pp. 80-91). Reston, VA: National Council of Teachers of Mathematics.

Edens, K., \& Potter, E. (2008). How students "unpack" the structure of a word problem: Graphic representations and problem solving. School Science and Mathematics, 108, 184196. 
Edwards, S., Maloy, R. W., \& Anderson, G. (2009). Reading coaching for math problems. Literacy Coaching Clearinghouse. Retrieved January 12, 2010, from http://www.literacycoachingonline.org/briefs/Reading_Coach_for_Math.pdf.

Fuchs, L. S., Fuchs, D., \& Prentice, K. (2004). Responsiveness to mathematical problemsolving instruction: Comparing students at risk of mathematics disability with and without risk of reading disability. Journal of Learning Disabilities, 37, 293-306.

Griffin, C. C., \& Jitendra, A. K. (2009). Word problem-solving instruction in inclusive third grade mathematics classrooms. Journal of Educational Research, 102, 187-202.

Gutstein, E. (2006). Reading and writing the world with mathematics: Toward a pedagogy for social justice. New York, NY: Routledge.

Hart, J. (1996). Effects of personalized word problems. Teaching Children Mathematics, 2(8), 504-505.

Hembree, R. (1992). Experiments and relational studies in problem solving: A meta-analysis. Journal for Research in Mathematics Education, 23, 242-273.

Herman, J. L. (1998). The state of performance assessments. The School Administrator, $55(11), 17-22$.

Higgins, K. M. (1997). The effect of year-long instruction in mathematical problem solving on middle-school students' attitudes, beliefs, and abilities. The Journal of Experimental Education, 66(1), 5-28.

Hoff, D. J. (2001) Reading mastery is new requisite for solving math. Education Week, 21(14), 1-2.

Hyde, A. (2006). Comprehending math: Adapting reading strategies to teach mathematics, K-6. Portsmouth, NH: Heinemann.

Immergut, B. (2003). Math master: Solving word problems. Franklin Lakes, NJ: Career.

Jitendra, A. K., Sczesniak, E., \& Deatline-Buchman, A. (2005). An exploratory validation of curriculum-based mathematical word problem-solving tasks as indicators of mathematics proficiency for third graders. School Psychology Review, 34, 358-371.

Johnson, B., \& Christensen, L. (2012).Educational research: Quantitative, qualitative, and mixed approaches (4th ed.). Thousand Oaks, CA: Sage.

Jonassen, D. H. (2003) Designing research-based instruction for story problems. Educational Psychology Review, 15, 267-296.

Kohn, A. (2001). Fighting the tests: A practical guide to rescuing our schools. Phi Delta Kappan, 82(5), 348-357.

Kosko, K. W., \& Wilkins, J. L. M. (2010). Mathematical communication and its relation to the frequency of manipulative use. International Electronic Journal of Mathematics Education, 5(2), 79-90.

Leppanen, U., Niemi, P., Aunola, K., \& Nurmi, J. (2006). Development of reading and spelling Finnish from preschool to grade 1 and grade 2. Scientific Studies on Reading, 10, $3-30$.

Lerkkanen, M. K., Rasku-Puttonen, H., Aunola, K., \& Nurmi, J. (2005). Mathematical performance predicts progress in reading comprehension among 7-year olds. European Journal of Psychology of Education, 20(2), 121-137.

Lincoln, Y. S., \& Guba, E. G. (1985). Naturalistic inquiry (7th ed.). Newbury Park, CA: Sage Publications.

Mason, S. F. (1980). Problem solving in school mathematics: An annotated bibliography. In S. Krulik \& R. E. Reys (Eds.), Problem solving in school mathematics: 1980 National 
Council of Teachers of Mathematics Yearbook (pp. 228-241). Reston, VA: National Council of Teachers of Mathematics.

National Council of Teachers of Mathematics. (2000). Principles and standards for school mathematics. Reston, VA.

National Council of Teachers of Mathematics. (2006). Curriculum focal points for prekindergarten through grade 8 mathematics. Reston, VA.

No Child Left Behind (NCLB) Act of 2001, Pub. L. No. 107-110, 115, Stat. 1425 (2002).

Oladunni, M. O. (1998). An experimental study on the effectiveness of metacognitive and heuristic problem solving techniques on computational performance of students in mathematics. International Journal of Mathematical Education in Science and Technology, 26, 867-874.

Pearce, D. L. \& Bader, L. A. (2001). Reading about reading: A survey revisited. Paper presented at the meeting of the College Reading Association, Orlando, FL.

Pearce, D. L. \& Davison, D. M. (1988). Teacher use of writing in the junior high mathematics classroom. School Science and Mathematics, 88(1), 6-15.

Pearce, D. L. \& Reynolds, N. G. (2004). Recommended procedures for reading mathematics in current and past content/secondary reading textbooks. In J. A. F. Dugan, P. E. Linder, M. B. Sampson, B. Brancato, \& L. Elgish-Piper (Eds.), Celebrating the Power of Literacy: 2004 College Reading Association Yearbook (pp. 394-412). Commerce, TX: College Reading Association.

Polya, G. (1945, 2009). How to solve it. Princeton, NJ: Princeton University Press.

Rousseau, C. K. (2004). Shared beliefs, conflict, and a retreat from reform: The story of a professional community of high school mathematics teachers. Teaching and Teacher Education, 20, 783-796.

Sanchez, J. C., Encinas, L. H., Fernandez, R. L., \& Sanchez, M. R. (2002). Designing hypermedia tools for solving problems in mathematics. Computers \& Education, 38, 303317.

Schoenfeld, A. H. (1979). Explicit heuristic training as a variable in problem-solving performance. Journal for Research in Mathematics Education, 10(3), 173-187.

Sibbald, T. (2009). The relationship between lesson study and self-efficacy. School Science and Mathematics, 109, 450-460.

Stemler, S. (2001). An overview of content analysis. Practical Assessment, Research \& Evaluation, 7(17). Retrieved January 12, 2010 from http://PAREonline.net/getvn. asp? $\mathrm{v}=7 \& \mathrm{n}=17$.

Stuart, C., \& Thurlow, D. (2000). Making it their own: Preservice teachers' experiences, beliefs, and classroom practices. Journal of Teacher Education, 51, 113-121.

Superfine, A. C. (2009). The "problem" of experience in mathematics teaching. School Science and Mathematics, 109, 7-19.

Texas Education Agency (TEA). (2009). TAKS released tests. Retrieved January 12, 2010 from http://www.tea.state.tx.us/student.assessment/taks/released-tests.

TEA. (2011). Assessment and testing. Retrieved January 12, 2010 from http://www.tea.state.tx.us/ student.assessment.html.

Vilenius-Tuohimaa, P., Aunola, K \& Nurmi, J. (2008) The association between mathematical word problems and reading comprehension. Educational Psychology, 28(4), 409-426.

Weber, M. G. (1966). The demon of arithmetic-reading word problems. In A. J. Harris (Ed.), Readings on reading instruction (pp. 314-318). New York: David McKay. 
Xin, Y. P., \& Zhang, D. (2009). Exploring a conceptual model-based approach to teaching situated word problems. The Journal of Educational Research, 10(6), 427-441.

\section{Authors}

Daniel L. Pearce, Professor, Department of Educational Leadership, Curriculum and Instruction, College of Education, Texas A\&M University, 6300 Ocean Drive, Corpus Christi, Texas 78412, USA; dan.pearce@ tamucc.edu

Faye Bruun, Assistant Professor, Assistant Professor, Department of Educational Leadership, Curriculum and Instruction, College of Education, Texas A\&M University - 6300 Ocean Drive, Corpus Christi, Texas 78412, USA; faye.bruun@tamucc.edu

Kimberly Skinner, Assistant Professor, Louisiana State University, School of Education, 215 Peabody Hall, Baton Rouge, LA 70803, USA; kskinner@lsu.edu.

Claricia Lopez-Mohler, Administrator, Corpus Christi ISD and Adjunct Professor, Department of Educational Leadership, Curriculum and Instruction, College of Education, Texas A\&M University - 6300 Ocean Drive, Corpus Christi, Texas 78412, USA; claricia.mohler@tamucc.edu 


\section{Appendix}

\section{Interview Guide}

Interviewer: I will be asking you some questions about teaching mathematics, specifically mathematics word problems. With your permission, I would like to record the interview. Before I can begin the interview, I must ask you to sign a consent form. Here is the consent form, please look it over. Do you have any questions? If not, please sign it.

Record the following information on the audio-tape.

Name of interviewer

Date

Teacher's position and grade level

School and district

Gender

Number of years of experience at that grade level

Total number of years of experience

Level of education

How many hours a day do you teach math?

What is the estimated ethnic make-up of your school?

What do you think the SES of your school is?

\section{Interview Questions}

1. Describe any difficulties that your students have when working mathematical word problems.

2. How important is the ability to solve word problems for your students? Why?

3. What do you think the cause of their difficulty to solve word problems is?

4. How do you feel about teaching word problems?

5. How would you rate your success in teaching students to solve word problems?

Interviewer: I am now going to ask you a couple of questions that are similar. The first two questions address what you do and the next two questions address what you have the students do.

6. What specific strategies do you use when teaching word problems?

7. Where did you learn them?

8. What specific strategies do you teach the students to use to solve word problems?

9. Where did you learn them?

10. What would you consider your best method for teaching word problems?

11. Has the emphasis on word problems changed in the past few years? Why or why not?

12. Approximately how many hours of in-service dealing specifically with working with word problems have you had in the past three years? 